\title{
La incidencia económica del Fondo Especial del Tabaco en Misiones (Argentina). Estudio de caso, 2010-2018
}

\section{The economic impact of the Special Tobacco Fund in Misiones (Argentina). Case study, 2010-2018}

\author{
Lisandro Federico Fernández* \\ LeANDro TOMAS Amoretti*
}

\begin{abstract}
The research analyzed the participation of the Special Tobacco Fund (FET) in the collection value as a way to study its incidence in the income of producers and infer its link with the appropriate proportion by the collectors when comparing it with a theoretical price of competition. It was revealed that the FET contributions grew from $90 \%$ to $260 \%$ in the stockpile value, exhibiting a growing incidence in the subsistence of producers. The work was based on a case study, located in the province of Misiones, Argentina during the period 2010-2018.
\end{abstract}

Keywords: public policies, special tobacco fund, prices, Misiones, Argentina.

\begin{abstract}
Resumen
La investigación analizó la participación del Fondo Especial de Tabaco (FET) sobre sobre el valor de acopio como forma de estudiar su incidencia sobre los ingresos de los productores e inferir su vínculo con la proporción apropiada por los acopiadores al compararla con un precio teórico de competencia. De la investigación surgió que los aportes del FET crecieron de $90 \%$ a 260\% sobre el valor de acopio, exhibiendo una creciente incidencia del mismo en la subsistencia de los productores. El trabajo se basó en un estudio de caso, situado en la provincia de Misiones (Argentina) durante el período 2010-2018.
\end{abstract}

Palabras claves: políticas públicas, fondo especial tabaco, precios, Misiones.

\section{Introducción}

\footnotetext{
*Universidad Nacional de La Plata, correos e: lisandrofernandez85@gmail.com y leandroamoretti@gmail.com
} 
El complejo tabacalero tiene una estructura productiva de elevada importancia económica y social en diferentes territorios de la Argentina, el cual en las últimas décadas del siglo XX y principios del XXI reforzó la dependencia entre los actores que la componen; al mismo tiempo, la intervención estatal, mediante su política fiscal, contribuyó a sostener dicha estructura. Su configuración remite a la atención sobre el vínculo entre Estado y mercado, temática que constituye una extensa discusión en la teoría económica y sociológica. En efecto, desde la perspectiva neoclásica los mercados son (y deben ser) autorregulados, por lo que el Estado no debe intervenir en ellos o debe tener un rol subsidiario. Para esta corriente, los mercados implican intercambios con un precio determinado por la oferta y la demanda. Adicionalmente, los marginalistas convirtieron al mercado en un concepto abstracto y un mecanismo de asignación de recursos (Díaz-Cano y Tardivo, 2016).

En cambio, desde la sociología los intercambios forman parte de la estructura social. Esto implica que el mercado no tiene una existencia autónoma en la sociedad, ya que incluso en todas las sociedades anteriores al siglo XIX la economía se hallaba subordinada a relaciones sociales más amplias. De modo que los intercambios y la satisfacción de las necesidades materiales estaban determinadas por estructuras, comportamientos y motivaciones más allá de lo estrictamente económico (Colombo, 2008). En este orden, Polanyi (2011) señala que antes del siglo XIX la economía estaba arraigada en la sociedad. Desde la perspectiva de este autor, el intercambio se generó a causa de la división territorial del trabajo, y luego se crearon los espacios de comercio local, en consonancia con las regulaciones de las localidades y del poder político. Los inicios de los mercados locales se vieron acompañados por salvaguardas destinadas a proteger la organización económica en la sociedad con las prácticas del mercado. La armonía del mercado se logró gracias a patrones que restringieron su alcance, al mismo tiempo que buscaron asegurar su capacidad de funcionamiento dentro de límites estrechos (Polanyi, 2011).

Profundizando en este campo, la vertiente denominada Economía Política (dentro de la sociología económica) analiza las vinculaciones entre los estados, las leyes y los mercados en el contexto histórico de gobernanza. Ésta toma en cuenta el rol de los gobiernos y las leyes en la creación de características particulares de ciertos mercados (Fligstein y Dauter, 2007). Aquí el Estado contribuye a crear las instituciones de mercado y los mercados particulares, considerando las particularidades de las instancias oficiales en el desarrollo económico y la participación de las distintas clases sociales en las alianzas políticas gobernantes. Incluso postula la existencia de una relación de dependencia/complementariedad que existe entre Estado y mercado. El primero influye sobre el segundo estableciendo 
las reglas y el canal por el cual los recursos pueden ir de un lugar a otro (Swedberg, 2003).

Estas discusiones pueden trasladarse al caso de la actividad tabacalera en Argentina, para la cual análisis previos denominaron al vínculo entre Estado y mercado como tutela activa (Diez, 2010), en la cual la intervención estatal actúa por acción u omisión reproduciendo la desigualdad (García, 2014).

Con base en estas contribuciones como marco de referencia, el presente artículo busca aportar evidencia empírica acerca del rol de las políticas públicas en el sector tabacalero de Misiones, por medio del Fondo Especial del Tabaco (FET). Concretamente se analizó la determinación de los precios de acopio del tabaco tipo Burley y Criollo misionero, predominantes en Misiones, y a la vez se estableció una comparación con los precios de acopio de Brasil, para inferir la diferencia de precios pagados a productores, respecto a los de cercanía territorial. En ese sentido, el objetivo del trabajo es analizar el rol de la intervención estatal sobre la actividad tabacalera de la provincia de Misiones, particularmente en el sostenimiento de los pequeños productores. Para llevar a cabo la investigación, las preguntas que guían el presente artículo son: ¿De qué modo intervienen las políticas públicas económico-fiscales sobre el mercado tabacalero? ¿Qué rol tiene el FET en la provincia de Misiones? ¿Cuál es la incidencia de los subsidios del FET sobre los ingresos del sector primario?

La investigación se sustentó en una metodología basada en el estudio de caso: el FET en Misiones, la cual combinó elementos cuantitativos y cualitativos. El valor del estudio de caso radica en su carácter de estudio denso que, narrado en su diversidad, puede desentrañar sentidos generales. En particular, siguiendo a Stake (citado en Marradi et al., 2012) se utilizó el estudio de caso instrumental, que cumple el rol de mediación para la comprensión de un fenómeno que lo trasciende.

La unidad de análisis está conformada por el FET (como política pública) y las variables las constituyen los subsidios, los precios de acopio y un índice construido con el propósito de cuantificar la importancia de la intervención pública (ratio aporte del FET/precio de acopio). La escala territorial se suscribe a la provincia de Misiones (segunda en importancia de producción de tabaco en el país), y el período de estudio abarca de la campaña 2010/11 a la 2017/18, debido a que el punto de inicio está marcado por la revalorización del FET y la jerarquización política de la agricultura familiar, mientras que el punto de cierre alcanza a los últimos datos disponibles. De este modo, el caso de estudio aporta evidencia empírica y permite construir inferencias analíticas acerca de la vinculación entre políticas públicas y mercados, como una contribución a una temática más global que requerirá de futuras investigaciones para profundizar en sus alcances. 
El artículo se organiza del siguiente modo: luego de la presente introducción, en el primer apartado se exponen brevemente las condiciones de la producción tabacalera en la provincia de Misiones. A continuación se identifican los principales agentes de la cadena tabacalera de valor de Misiones, lo cual permite caracterizarla como un mercado oligopsónico. En la tercera sección se presenta al FET, con el propósito de identificar los orígenes, objetivos y la conformación y el destino de los recursos. En la sección número cuatro se presentan y analizan los resultados de la investigación, que estiman la magnitud de los aportes del FET sobre el precio de acopio del tabaco, así como la brecha con respecto a los precios de exportación y con el mercado brasileño. El trabajo culmina con las reflexiones finales en donde se sintetizan y condensan los principales aportes de la investigación.

\section{Caracterización de la producción tabacalera en la provincia de Misiones}

La provincia de Misiones está situada en el noreste de Argentina, limita con Brasil (al este), con Paraguay (al norte) y con la provincia de Corrientes (al sur). Su población total supera las 1,200,000 personas y su división político-territorial se basa en 17 departamentos, compuestos a su vez por 75 municipios. Su economía provincial representa $1.2 \%$ del PBI total nacional. Si bien es relativamente pequeña en comparación con el resto del país, al interior se estructura del siguiente modo (a valores promedio 2007-2013): 50.4\%, sector terciario; $37.5 \%$, secundario y $12.1 \%$, primario (Ministerio de Hacienda, 2018). ${ }^{1}$ Más allá de estas cifras, el sector primario representa uno de los sectores más dinámicos de Misiones, y por sus características, es de interés para el desarrollo social y político de la provincia, como se analizará a continuación.

La economía misionera presenta cuatros sectores productivos de relevancia: la cadena forestal, la yerbatera, la tabacalera y el turismo. Estas cadenas representan elevados niveles de participación en relación con el total nacional, y a su vez, las primeras tres de ellas explican aproximadamente 99\% de las exportaciones de la provincia (Ministerio de Hacienda, 2018). Asimismo, debido a la política de colonización y acceso a la tierra de la provincia de Misiones a principios del siglo XX, las tres cadenas agroindustriales constituyen un pilar de la organización económica y social

${ }^{1}$ El Ministerio de Hacienda y Finanzas Públicas recibió dicha denominación entre 2016 y 2018. A partir de allí adoptó el nombre de Ministerio de Hacienda y en la actualidad (2020) se denomina Ministerio de Economía. A lo largo del artículo se lo cita en la modalidad que corresponde según el año. 
de la agricultura familiar, estableciéndose como un actor social de gran dinamismo (Diez, 2010).

Según Scheinkerman (2009), en 2002 existían 25,359 explotaciones agropecuarias (EAP) Familiares en Misiones, que representan 91\% del total provincial, pero sólo tienen $43 \%$ de la superficie (unas 883,794 has) y se apropian del $51 \%$ del valor bruto de la producción de la provincia. ${ }^{2} \mathrm{~A}$ su vez, las EAP Familiares también representan $91 \%$ del trabajo permanente agrario provincial y $67 \%$ del trabajo transitorio por contratación directa. Estos datos muestran que la agricultura familiar se caracteriza por ser el sector mayoritario dentro de la estructura social agraria de Misiones y tiene un rol protagónico en la generación de empleo, pero al mismo tiempo convive con fuertes desigualdades socioeconómicas (Fernández, 2016).

En cuanto al sector tabacalero, la provincia de Misiones se destaca como uno de los principales territorios productivos: constituye la segunda en importancia a escala nacional, al alcanzar una producción de más de 29 mil 800 toneladas (campaña 2017/2018). ${ }^{3}$ Asimismo, representa 21\% de las exportaciones de tabaco ${ }^{4}$ de la Argentina. Particularmente, Misiones se destaca por ser la principal productora de tabaco Burley ${ }^{5}$ (representa $83 \%$ de la producción nacional) y también por su gran concentración de pequeños productores multicultivo. Cabe destacar que el crecimiento y especialización de la cadena tabacalera en Misiones comenzó en la década de los ochenta con la expansión del tipo de tabaco citado, sobre la base de una configuración económica y social particular ligada a las colonias de productores y a una historia de auto organización campesina (Diez y Re, 2015).

La producción tabacalera se basó tradicionalmente en áreas con fuerte presencia de productores que utilizaban mano de obra familiar y, dadas las altas demandas de fuerza de trabajo que implica su cultivo, tenían un peso social significativo en sus áreas de producción (Aparicio, 2009).

Dicha estructura se sostiene hasta la actualidad, ya que los pequeños productores (representativos hoy de la agricultura familiar) son el sector predominante en la producción primaria debido a que la actividad es intensiva en mano de obra. Por ejemplo, la variedad Burley requiere de 90 jornales/hectárea/año. Asimismo, la mitad de la producción se lleva a

${ }^{2} \mathrm{Al}$ momento de redactar el presente artículo se ignoran los resultados definitivos del Censo Nacional Agropecuario de 2018. Por ende, para la identificación de los pequeños productores, o EAPs familiares, se utilizan los datos procesados por Scheinkerman (2009).

${ }^{3}$ Secretaría de Agroindustria, 2019. Este organismo poseía rango ministerial entre 2016 y 2018 , al cual se lo denominaba Ministerio de Agroindustria, luego fue Secretaría de Agroindustria entre 2018 y 2019 y actualmente (2020) se denomina Ministerio de Agricultura, Ganadería y Pesca. A lo largo del artículo se lo cita en la modalidad que corresponde según el año.

${ }^{4}$ Ministerio de Hacienda (2019).

${ }^{5}$ El tabaco Burley misionero (flavour) tiene más cuerpos que otros tipos, por lo que su calidad es superior y en consecuencia se destina en parte a la exportación. 
cabo en explotaciones de hasta dos hectáreas. Por otro lado, se estima que en Misiones existen alrededor de 13,900 explotaciones de esa dimensión (72\% del total del país) (Ministerio de Hacienda, 2019). Estos valores denotan la importancia de la producción tabacalera dentro de la estructura social agraria misionera, pero especialmente en sus sectores más vulnerables.

Por otro lado, en la figura 1 se observa que la producción tabacalera se concentra territorialmente en la zona centro-sur de la provincia, particularmente en los departamentos de San Vicente (en primer lugar) y 25 de Mayo (en segundo lugar), mientras que el departamento con mayores volúmenes (medidos en toneladas) de acopio lo constituye Leandro $\mathrm{N}$. Alem. Es preciso tener en cuenta que en la provincia de Misiones se realiza 29\% del acopio a nivel nacional para el año 2018 (Ministerio de Hacienda, 2019).

Asimismo, la organización social del trabajo dentro de la cadena tabacalera se ha caracterizado como agricultura bajo contrato ${ }^{6}$ (Aparicio, 2009; Ministerio de Hacienda y Finanzas, 2016). Este tipo de vínculo entraña

\section{Figura 1}

\section{Provincia de Misiones y distribución territorial de la producción y acopio de tabaco}

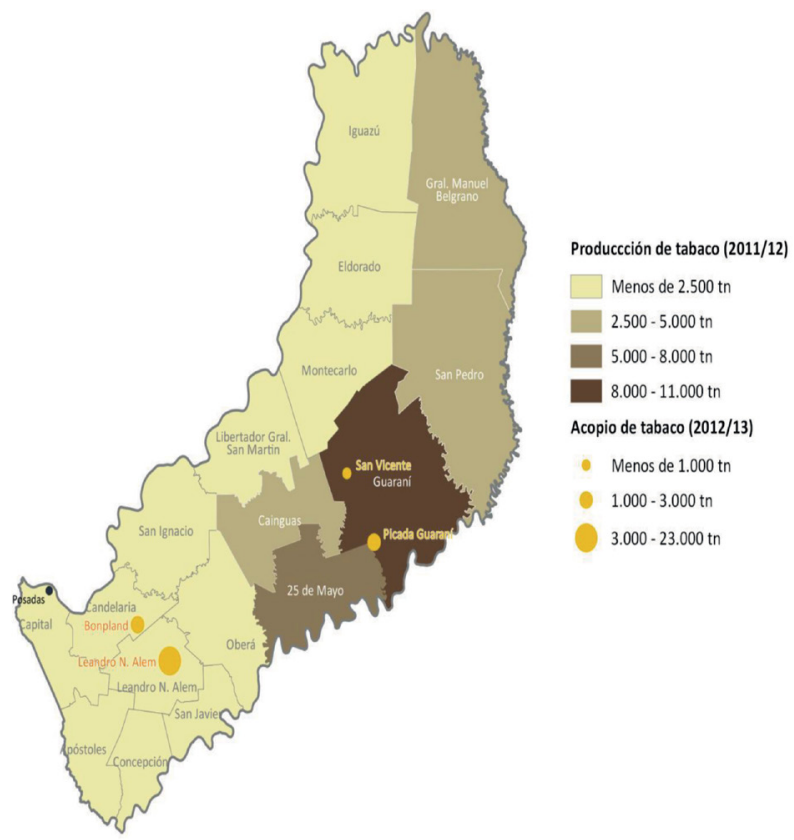

Fuente: Ministerio de Hacienda (2018: 24).

${ }^{6}$ Esta modalidad de vinculación ha crecido desde la década de los setenta, siendo parte de una estrategia de expansión de las grandes multinacionales agroindustriales a nivel mundial (Watts, 1990). 
una relación de dependencia (y subordinación) entre el pequeño productor primario y el sector acopiador, con lo cual se limitan los márgenes de decisión del primero, más allá de que dicha relación está solapada por contratos entre supuestas partes iguales. Por lo general, el pequeño productor recibe los insumos y materiales de trabajo por parte del acopiador, pero debe ajustarse a los estándares de productividad y calidad que éste le impone. El tipo de vínculo entre los productores y las empresas acopiadoras está vehiculizado mediante el apoyo técnico a través de la figura del instructor: con este nombre se identifica al técnico de las empresas acopiadoras que se constituye como enlace entre éstas y el productor.

De este modo, los contratos son impuestos por las empresas acopiadoras, los cuales permiten planificar y garantizar la producción de tabaco, escapar de todo riesgo y lograr niveles planificados de sobreproducción (García, 2014). Esta caracterización resulta central para comprender las características oligopsónicas del mercado, ya que permite la acumulación de la mayor parte de los beneficios en el sector acopiador.

Respecto a los datos sobre la producción tabacalera de Misiones se observa una elevada participación sobre el agregado nacional próxima a $28.7 \%$ (campańa 2017/2018). A continuación se exponen los datos más relevantes de las campañas 2010/2011, 2011/2012, 2012/2013, 2013/2014, 2014/2015, 2015/2016, 2016/2017 y 2017/2018.

\section{Tabla $1^{7}$}

Superficie, producción y porcentaje sobre el total nacional en Misiones.

Campañas 2010/2011-2017/2018 (en hectáreas, toneladas y porcentajes)

\begin{tabular}{lrrr}
\hline Campañaltipo & $\begin{array}{c}\text { Superficie } \\
\text { cosechada }(\mathrm{ha})\end{array}$ & \multicolumn{1}{c}{$\begin{array}{c}\text { Producción } \\
(\mathrm{kg})\end{array}$} & $\begin{array}{c}\text { Porcentaje de producción } \\
\text { sobre el total nacional }\end{array}$ \\
\hline $2010 / 2011$ & 26,211 & $36,159,509$ & $26.7 \%$ \\
\hline Burley & 25,518 & $35,204,004$ & $83.4 \%$ \\
Criollo Misionero & 693 & 955,505 & $100 \%$ \\
\hline $2011 / 2012$ & 21,812 & $29,805,854$ & $25.8 \%$ \\
Burley & 21,294 & $29,080,235$ & $81.9 \%$ \\
\hline Criollo Misionero & 518 & 725,619 & $100 \%$ \\
\hline $2012 / 2013$ & 22,728 & $27,456,914$ & $24.4 \%$ \\
\hline
\end{tabular}

${ }^{7}$ No fueron incorporados los datos referidos al tabaco Criollo Argentino debido a su aporte marginal, próximo a las cinco toneladas. 
Tabla 1 (continuación)

\begin{tabular}{lrrr}
\hline Campañaltipo & $\begin{array}{c}\text { Superficie } \\
\text { cosechada }(\mathrm{ha})\end{array}$ & \multicolumn{1}{c}{$\begin{array}{c}\text { Producción } \\
(\mathrm{kg})\end{array}$} & $\begin{array}{c}\text { Porcentaje de producción } \\
\text { sobre el total nacional }\end{array}$ \\
\hline Burley & 22,362 & $27,013,893$ & $80.4 \%$ \\
\hline Criollo Misionero & 366 & 443,021 & $100 \%$ \\
\hline 2013/2014 & 24,178 & $37,341,520$ & $29.4 \%$ \\
\hline Burley & 23,768 & $36,826,527$ & $85.1 \%$ \\
\hline Criollo Misionero & 410 & 514,993 & $100 \%$ \\
\hline 2014/2015 & 17,585 & $25,313,033$ & $23.2 \%$ \\
\hline Burley & 17,331 & $25,008,109$ & $79.1 \%$ \\
\hline Criollo Misionero & 254 & 304,924 & $100 \%$ \\
\hline 2015/2016 & 12,715 & $18,149,127$ & $19.4 \%$ \\
\hline Burley & 12,384 & $17,873,156$ & $77.7 \%$ \\
\hline Criollo Misionero & 331 & 275,971 & $100 \%$ \\
\hline 2016/2017 & S/D & 466,346 & $29.3 \%$ \\
\hline Burley & S/D & $29,406,457$ & $83.0 \%$ \\
\hline Criollo Misionero & 308 & 480,328 & $77.7 \%$ \\
\hline 2017/2018 & 21,752 & $33,890,721$ & $28.7 \%$ \\
\hline Burley & $29,877,914$ & $78.9 \%$ \\
\hline Criollo Misionero & S/D & & $71.0 \%$ \\
\hline
\end{tabular}

Fuente: elaboración propia con base en la Secretaría de Agroindustria (2019).

Cabe mencionar el particular crecimiento para las variables sintetizadas en la tabla 1 en relación con la campaña 2015/2016. En la siguiente (2016/17), la superficie cosechada creció $73.5 \%$, la producción $89.4 \%$ y también el valor de las exportaciones $82.4 \%$. Esta situación se explica por dos campañas seguidas con elevadas pérdidas (2014/2015 y 2015/2016), ligadas a la sequía de $2015 .{ }^{8}$

No obstante, la cadena tabacalera cuenta con una política pública de alto impacto en la producción y en la vida de sus productores. En particular se destaca la gran cantidad de recursos asignados y el rol de dichos fondos en un mercado con características oligopsónicas, esto es, un mer-

\footnotetext{
${ }^{8}$ En Misiones, los meses de trasplante para el tabaco son septiembre y octubre, en tanto que los de cosecha son diciembre y enero.
} 
cado con pocos demandantes en el mercado de insumos, de tal modo que pueden ejercer predominio en la determinación de cantidades y precios. Por ejemplo, para 2018 el total de recursos transferidos por el FET alcanzó los \$2,719 millones. Este monto es sin dudas relevante para la economía provincial. Una simple comparación con el impuesto inmobiliario de la provincia indica que los fondos asignados por el FET en 2018 equivalieron a 13.8 veces lo aportado por el impuesto inmobiliario provincial. ${ }^{9}$ Otra variable de referencia es el total de gastos corrientes devengados en 2018 por parte del gobierno provincial, los cuales ascendieron a $\$ 52,539$ millones. ${ }^{10}$ Los números exhibidos dan cuenta de la relevancia de FET para la economía provincial.

Bajo esta caracterización la presente sección introduce en primer lugar un breve análisis de la producción tabacalera, que puntualiza el caso del FET y evalúa datos del período 2010-2018, para luego realizar un abordaje crítico de las condiciones de concentración del mercado del tabaco.

\section{Dinámica de un mercado oligopsónico}

La estructura y la dinámica del mercado de tabaco en Misiones presenta características que se alejan de la situación de competitividad y autorregulación. En particular, una de las variables que transmite información acerca de los grados de competencia del mercado está representada por el precio de acopio de tabaco, condicionado por un conjunto de empresas oligopsónicas que obtienen un precio favorable, lo cual ubica en una posición de inferioridad y dependencia a los más de 13 mil pequeños productores del sector. Esto se debe a que la cadena de valor del tabaco se estructura con base en un conjunto de actores concentrados en la etapa industrial. A continuación se presenta un diagrama que grafica las relaciones de la cadena.

El diagrama 1 representa la estructura del mercado de tabaco en Misiones, en la cual se destaca el rol de las empresas acopiadoras en el proceso productivo y el circuito de comercialización, de modo similar a lo que ocurre a nivel nacional. En este sentido, sobresale el rol y el peso que tienen CTM Cooperativa Agroindustrial (ex Cooperativa Tabacalera de Misiones) y Massalin Particulares filial de Philips Morris International, en la apropiación de valor. Por caso, en la campaña 2017/2018 ambas empresas se apropiaron de 75.6\% del valor acopiado del tabaco Burley,

\footnotetext{
${ }^{9}$ La recaudación del impuesto inmobiliario para el año 2018 totalizó en \$195.8 millones (Dirección General de Rentas de la provincia de Misiones, 2019).

${ }^{10}$ Consolidado administración pública no financiera (Ministerio de Hacienda, Finanzas, Obras y Servicios Públicos de Misiones, s/f).
} 


\section{Diagrama 1}

\section{Cadena de valor del tabaco, principales organizaciones}

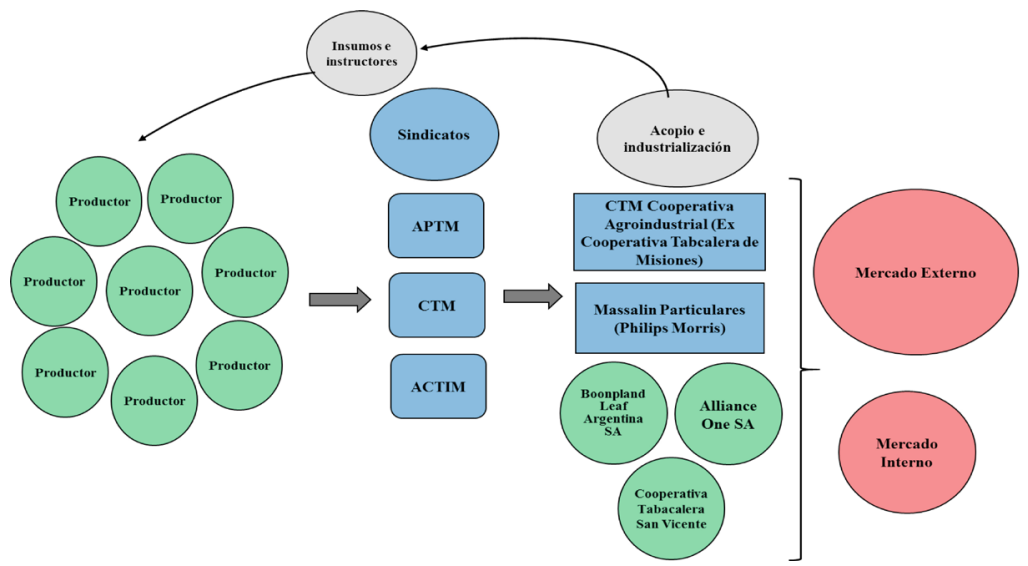

Fuente: elaboración propia con base en la Secretaría de Agroindustria (2019) y periódico Misiones Online (2018).

registrando valores similares en las campañas anteriores, excepto la correspondiente a los años 2014/2015 donde la participación alcanzó el 66.1 por ciento. ${ }^{11}$

De este modo, con dos actores apropiándose de la mayor parte del valor generado, estamos en presencia de un mercado oligopsónico, en el cual se identifican por un lado los productores tabacaleros, con sus respectivos sindicatos, y por otro, un pequeño grupo de empresas acopiadoras, dentro del cual dos de ellas concentran las dos terceras partes del acopio. Como consecuencia se reproduce una relación económica y productiva asimétrica, expresándose primordialmente a través de la diferencia entre el precio de compra del tabaco y su precio de competencia teórico, como se analizará más adelante.

El proceso de industrialización y comercialización presenta un primer paso en el cual las empresas acopiadoras reciben los fardos de tabaco y realizan una clasificación según tipo y calidad. En el acopio se realizan tareas de acondicionamiento, picking, clasificación, separación, secado y despalillado, con el fin de controlar aspectos de humedad y temperatura para cuidar la calidad del producto. Una vez clasificados y adecuados los fardos, se dividen según su destino, orientándose predominantemente en un porcentaje próximo a $80 \%$ al mercado externo. Los tipos de tabaco Burley, producido centralmente en Misiones, y Virginia son los principales productos de exportación del mercado (Ministerio de Agricultura, Ganadería y Pesca, s/f).

${ }^{11}$ Elaboración propia con base en la Secretaría de Agroindustria (2019). 
Sin embargo, sólo un conjunto limitado de empresas canaliza las exportaciones al resto del mundo, entre las que se encuentran Alliance One (vinculada a British American Tobacco, BAT) y Phillips Morris (Massalin Particulares); las cooperativas que logran acceder al mercado externo lo hacen mediante dealers. El comercio exterior argentino es de suma importancia para el sector: durante el período 2006-2018 las exportaciones de tabaco promediaron los 328 millones de dólares, siendo Misiones la segunda provincia en importancia exportadora con $21 \%$ sobre el total (Ministerio de Hacienda, 2019). Los tres principales destinos de exportación son China, Bélgica y Paraguay.

Posteriormente, con los fardos destinados al mercado interno se completa el proceso industrial hasta la obtención de las hebras (materia prima) para la elaboración de cigarrillos. La etapa de venta en el mercado interno se encuentra fuertemente concentrada, ya que Massalin Particulares y BAT suman $89 \%$ de las ventas totales, mientras que $11 \%$ restante está en manos de empresas chicas.

Como se aprecia en este apartado, el sector se encuentra concentrado en pocos actores, y en este contexto actúan las políticas públicas vinculadas, siendo la más importante el Fondo Especial del Tabaco, que se analiza a continuación.

\section{Fondo Especial del Tabaco: presentación del caso}

La provincia de Misiones cuenta con larga experiencia en políticas públicas destinadas a los pequeños productores. Desde principios de la década de los noventa, la expansión capitalista del agro provincial provocó la crisis de la agricultura familiar, lo que motivó la implementación de programas y proyectos de desarrollo rural, financiados por diferentes organismos. Sus instrumentos de intervención comunes consistían en microcréditos, subsidios, asistencia técnica y apoyo organizativo (Arzeno et al., 2015). Estas iniciativas públicas se combinaban con el trabajo de las ONG y su apoyo a las organizaciones de pequeños productores, las cuales participaron en la instrumentación de diversos programas (Schiavoni et al., 2006).

Dicho proceso exhibe continuidades y variantes en los últimos años: desde 2008 se observan cambios en la estructura del Estado, con la creación de áreas que atienden específicamente a la agricultura familiar en la provincia de Misiones. A partir de ese momento, existió una creciente jerarquización institucional de la agricultura familiar en la provincia, tanto por el fortalecimiento de programas y secretarías como por el hecho de que se sancionaron leyes provinciales destinadas a visibilizar 
y fortalecer las actividades que desarrollan los agricultores familiares, que involucran la formalización de las ferias, el financiamiento, la creación de registros y la revalorización de su rol productivo (Fernández, 2016).

$\mathrm{Al}$ centrar la mirada en la actividad tabacalera, se observa que en nuestro país ésta se encuentra regulada por el Decreto Ley 19,800 (BORA, 1972) y sus sucesivas modificaciones. Esta ley estableció el carácter permanente del sistema de subsidios instrumentado de forma transitoria por la Ley 17,175 (BORA, 1967). Sin embargo, hasta el presente ha sufrido una gran cantidad de cambios que distancia la normativa actual de la original.

En este sentido, corresponde destacar las modificaciones instrumentadas en el marco del proceso de liberalización y desregulación de inicios de la década de los noventa, las cuales eliminaron funciones estatales, por ejemplo la determinación del precio, y descentralizaron de responsabilidades en las provincias, en particular el diseño y la ejecución de los planes de apoyo indirecto (BORA, 1991a; BORA, 1991b y BORA, 1993) (García, 2014: 128).

No obstante, dicho retroceso fue diferente a otros casos de disolución de organismos y entes reguladores, ya que si bien el FET presentó transformaciones relevantes, se sostuvo como un subsidio directo, manteniendo un sobreprecio de acopio y reproduciendo un vínculo dependiente entre los productores y las empresas acopiadoras. En este sentido, García sostiene que "la intervención estatal actúa -por acción u omisión- institucionalizando la subordinación a partir del fomento de modalidades contractuales de relacionamiento entre agricultores y agroindustria" (2014: 148). En un sentido similar, pero desde una perspectiva histórica y relacional, Diez (2010) caracteriza la intervención estatal en la producción de tabaco como una tutela activa.

Asimismo, cabe mencionar la suscripción de Argentina a los acuerdos establecidos en la Ronda de Uruguay bajo el marco del General Agreement on Tariffs and Trade (GATT) de la Organización Mundial del Comercio (OMC) durante la década mencionada (1995), que limitaron los subsidios directos a la producción, también llamados ayuda interna de la caja ámbar, ${ }^{12}$ Ley 24,425 (Ministerio de Justicia y Derechos Humanos, 1995). Esta última medida entró en vigencia en 1997, comprometiéndose a un camino de reducción hasta alcanzar los 75 millones de dólares (USD) en 2004.

Luego, en 1999 a través de la Resolución 785 de la entonces Secretaría de Agricultura, Ganadería, Pesca y Alimentación (SAGPyA) los POAs

\footnotetext{
${ }^{12}$ En la terminología de la Organización Mundial del Comercio, la ayuda interna o subsidios en el marco del Acuerdo Agrícola se clasifican en caja ámbar: subvenciones directas permitidas en forma limitada, caja verde: ayuda no vinculada directamente la producción, sin efectos distorsivos que se encuentran permitidas, y caja azul: subsidios vinculados a programas de limitación de la producción.
} 
(Programa Operativo Anual) fueron definidos como modalidad de instrumentación de proyectos por parte del Programa de Reconversión de Áreas Tabacaleras (PRAT) de la propia secretaría, siendo un instrumento correspondiente a la caja verde, conforme a la OMC. Si bien esta modalidad tuvo una participación secundaria en la movilización de recursos del FET, una vez alcanzado el tope de USD \$75 millones por parte del subsidio directo, su participación relativa creció notablemente siendo en los últimos años el principal instrumento de transferencia de recursos.

Asimismo, se debe mencionar la última modificación del sistema referida al financiamiento de las obras sociales del sector, realizada mediante la Ley 26,467 (BORA, 2009). Allí se definió una alícuota adicional, del 0.35\% (3.5 por mil) de la base imponible del FET, ${ }^{13}$ para financiar las obras sociales sindicales del sector tabacalero. Si bien no se ha detallado cada uno de los cambios de la ley, ${ }^{14}$ las modificaciones seleccionadas indican de qué manera fueron redefiniendo la normativa reguladora del FET. Esto ha implicado la conformación de una composición tendiente a contener diversos intereses en el plano nacional y provincial.

En la actualidad los artículos vigentes de la ley definen por un lado la estructura de ingresos del FET, determinados en función del precio de los cigarrillos, y por otro, la estructura de su distribución, establecida por la normativa, los gobiernos nacionales y provinciales, así como las organizaciones productivas del sector.

Desde el lado de los recursos, el fondo se constituye mediante la recaudación de un impuesto ad valorem de 7.35\% (7\% sin afectación específica y $0.35 \%$ destinado a las obras sociales tabacaleras), más un adicional fijo que es actualizado en función del precio promedio ponderado de un atado de cigarrillos. ${ }^{15}$ Luego se aplica un alícuota del $1 \%$, la cual aporta fondos a la cadena de comercialización, quedando por fuera del esquema bajo análisis. En la tabla 2 se resume el esquema de recursos que componen el FET.

Respecto a la estructura de distribución, en el diagrama 2 se presenta la división entre los componentes definidos por los artículos 27 y 28 de la Ley 19,800 (BORA, 1972). Este último establece la aplicación del subsidio directo. Sin embargo, dado el tope de USD \$75 millones acordado en el marco de los acuerdos de la OMC, los fondos excedentes se instrumentan mediante los POAs (80\%). Por su parte, el artículo 27 define la absorción de $20 \%$ de los recursos del FET, de los cuales $3 \%$ es canalizado por medio del Instituto Interamericano de Cooperación para la Agricultura (IICA), cuyo objetivo es mejorar la calidad productiva.

\footnotetext{
${ }^{13}$ Precio final del atado de cigarrillos excluyendo el impuesto adicional de emergencia y el IVA.

${ }^{14}$ Para ver en detalle, $c f r$. García (2014: 128-129).

${ }^{15}$ Para el primer semestre de 2019 al monto adicional alcanza un valor de $\$ 2.4$.
} 


\section{Tabla 2}

\section{Alícuotas de las fuentes que componen los recursos del FET}

\begin{tabular}{lll}
\hline \multicolumn{1}{c}{ Alícuota } & \multicolumn{1}{c}{ Fuente } & \multicolumn{1}{c}{ Destino } \\
\hline $7 \%$ & Sobre el precio total de venta al público & Subsidio y POA \\
$0.35 \%$ & Sobre el precio total de venta al publico & Obras sociales \\
$1 \%$ & Sobre el precio de venta al público & Cadena de comercialización \\
Adicional fijo & Actualizable semestralmente & $\begin{array}{l}\text { Subsidio, POA y } \\
\text { comercialización }\end{array}$
\end{tabular}

Fuente: elaboración propia con base en las Leyes 19,800 (BORA, 1972) y 26,467 (BORA, 2009).

Mientras tanto, 97\% restante debe destinarse a compensar los déficits provinciales del FET y a atender los problemas económicos y sociales de los productores minifundistas (POAs 20\%).

En contraste con el esquema indicado por la Ley $(80 \% / 20 \%)$ en donde el componente más relevante ha sido históricamente al subsidio directo, el tope USD $\$ 75$ millones y la conformación de POAs de $80 \%$ ha determinado una nueva estructura entre POAs y subsidios, invirtiendo su

\section{Diagrama 2 \\ Esquema de distribución del FET}

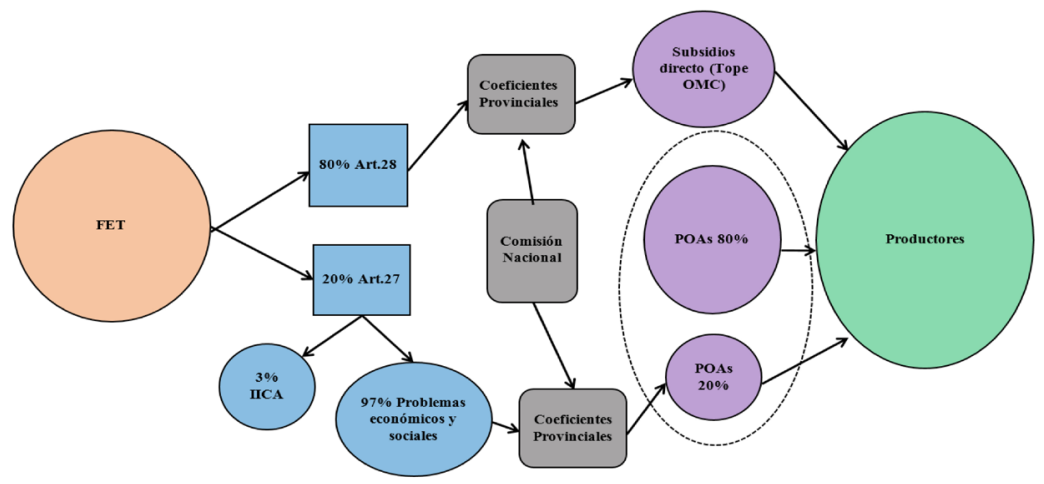

Fuente: elaboración propia con base en AGN (2018) y Ley 19,800 (BORA, 1972).

participación relativa. En otras palabras, al comenzar a operar el límite al subsidio o sobreprecio, los POAs, tanto del componente de $80 \%$ como de $20 \%$, han ganado participación relativa hasta alcanzar un lugar predominante respecto al total de recursos transferidos. Por ejemplo, para la campańa 2017/2018 la provincia de Misiones recibió \$2,719 millones mediante el FET, desagregado en $\$ 577$ millones vía sobreprecio (21\%) y 
\$2,142 millones vía POAs (79\%). ${ }^{16}$ Estos valores representaron 29\% de la distribución total del FET para 2018. ${ }^{17}$

Asimismo, cabe mencionar el orden de prioridades establecido en el artículo 29 de la Ley 19,800 (BORA, 1972) para todos los recursos aplicados por el FET, que se cita a continuación:

a) Pagar a los productores el importe establecido en el inciso b) del artículo $12 .^{18}$

b) Colaborar en el mejoramiento de técnicas de producción, a través de organismos de investigación nacional y provinciales.

c) Apoyar la formación de existencias adecuadas de tabaco que permitan asegurar un abastecimiento estable a la industria y a la exportación.

d) Propiciar sistemas de producción y comercialización cooperativa entre los productores tabacaleros.

e) Concurrir al ordenamiento de la producción y de la comercialización del tabaco.

f) Promover la conversión, complementación y diversificación agraria en las zonas tabacaleras.

g) Atender los gastos que origine el funcionamiento de la comisión nacional asesora permanente del tabaco y de los Organismos Provinciales de aplicación.

El ordenamiento señalado no indica una priorización clara de la diversificación de las zonas tabacaleras. Sin embargo, el artículo 27 de la ley (componente del 20\%) sí define como destino de los recursos la atención de los problemas económicos y sociales de los pequeńos productores tabacaleros. De este modo se identifica un elemento cualitativamente distintivo entre los POAs de $20 \%$ y de los POAs del $80 \%$.

Particularmente, de acuerdo con la información publicada por la Auditoría General de la Nación (AGN, 2018), la provincia de Misiones presenta los coeficientes de participación más elevados para la asignación de los POAs de $20 \%$. Sin embargo, el propio organismo ha planteado cuestionamientos concretos a la falta de ejecución de dichos fondos (AGN, 2018).

También Misiones ostenta una participación relevante en cuanto la recepción de POAs agregados, dado el aporte a la producción nacional y a la gran cantidad de pequeños productores existentes en la provincia. Incluso el gobierno provincial ha impulsado diferentes políticas con el

\footnotetext{
${ }^{16}$ Secretaría de Agroindustria (2019).

${ }_{17}$ Ministerio de Hacienda, Subsecretaría de Programación Microeconómica, Secretaría de Política Económica (2019).

${ }^{18}$ Se refiere al subsidio directo otorgado por el FET.
} 
objetivo de consolidar la agricultura familiar y la sostenibilidad ambiental de la misma (Fernández, 2016), para las cuales el FET es postulado como una de las fuentes de su financiamiento.

En síntesis, la aproximación realizada en la presente sección al sistema conformado por el FET aporta elementos para su caracterización, describiendo brevemente los cambios recientes más relevantes. Precisamente se ha subrayado la centralidad asumida por los POAs en la economía de la región, impactando directamente sobre las condiciones de producción y de ingresos de los productores primarios tabacaleros.

\section{Resultados: análisis de la importancia del FET}

En función del objetivo del análisis, se presenta en la gráfica 1 la evolución del precio de acopio total pagado en las últimas cuatro campañas y la participación del subsidio directo aportado por el FET.

La gráfica 1 expone la relevancia del subsidio directo otorgado por el FET en el precio final, el cual alcanza una participación de 35.6\% del valor de acopio total para el caso del tabaco Burley en la última campaña analizada. Es decir, de los $\$ 54.7$ obtenidos por el productor por cada kilo de tabaco $\$ 19.5$ fueron aportados por el sobreprecio, transferidos mediante el FET, y $\$ 35.2$ por la empresa acopiadora. El importe abonado por el FET y su peso relativo en el precio final revela tanto la dependencia de la industria del fondo de referencia como las características de concentración del mercado, el cual carece de un precio de acopio competitivo.

\section{Gráfica 1}

Precio de acopio total de tabaco Burley y Criollo. Participación del subsidio directo (FET), campañas 2010/11-2017/2018 (en porcentajes)

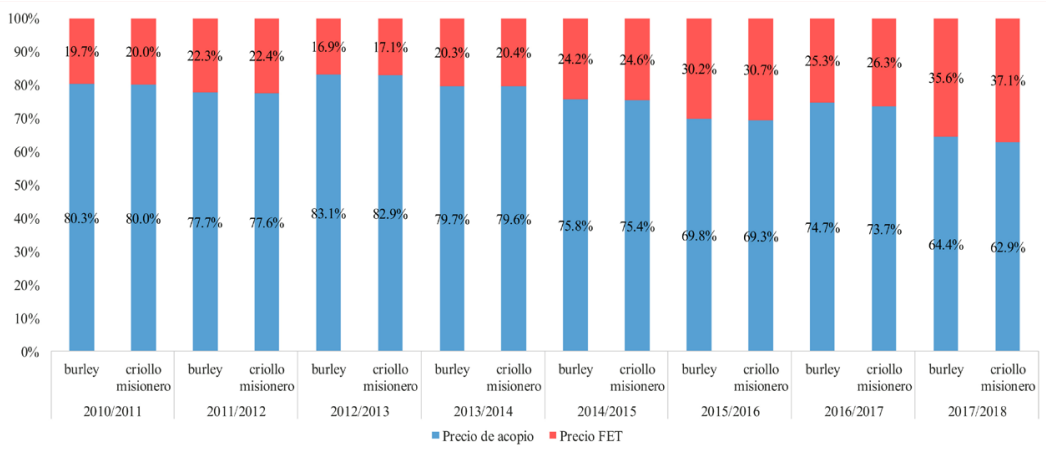

Fuente: elaboración propia con base en la Secretaría de Agroindustria (2019). 


\subsection{Brecha de precios}

Uno de los antecedentes del estudio de los precios de acopio del tabaco lo constituye el trabajo de Sturzenegger (2016), quien investigó el caso de la provincia de Jujuy respecto a la distancia entre los valores de acopio y un precio teórico de competencia (asociado al precio de exportación). Su trabajo sostiene la existencia de una brecha entre ambos valores, lo que constituye una extracción de valor por parte de los acopiadores a los productores (Sturzenegger, 2016). Según su estudio, para la campaña 2015/2016, producto de la devaluación y la recomposición del FET (como consecuencia del incremento de la alícuota del impuesto interno a los cigarrillos de 0.6 a 0.75$),{ }^{19}$ la brecha entre el precio de acopio y el precio teórico de competencia hubiese sido de 67 por ciento.

La estimación mencionada se realizó sobre la base del precio promedio de exportación del tabaco, el cual se toma como proxy del precio teórico de competencia. Si bien esta discusión excede los alcances de la presente investigación, tomamos aquí la premisa (Sturzenegger, 2016) de que en el mercado de exportación tanto desde el lado de la oferta como de la demanda actúan muchos agentes comercializadores, mientras que, como ya se caracterizó, los agentes compradores de los productos primarios que luego exportan son escasos. De aquí que la brecha entre el precio de acopio y el precio de exportación sea un indicador del margen apropiado por las empresas oligopsónicas. La información para las campañas 2010/11-2017/18 se presenta en la tabla 3.

La información de la tabla 3 permite apreciar con claridad la brecha entre el precio al que los acopiadores compran y venden el tabaco. Así, dicha magnitud oscila entre $197.1 \%$ y $274.9 \%$ para el período bajo estudio. No obstante, esta apreciación debe considerarse simplemente como un indicio, ya que al precio de exportación corresponde descontarle impuestos, pérdidas, costos logísticos y de procesamiento (despalillado y desvenado). Más allá de esto, se infiere que dicha brecha exhibe la proporción de valor apropiada por las empresas exportadoras que obtienen una utilidad de la condición concentrada del mercado tabacalero, exponiendo una de las consecuencias de la estructura productiva y comercial del tabaco.

Adicionalmente, en la tabla 3 se realizó la comparación de los precios de acopio (sin los aportes del FET) con Brasil (tabaco Burley tipo B1). $\mathrm{Al}$ analizar la brecha entre ambas variables, se infiere la diferencia en favor de los precios pagados a productores de cercanía territorial y similitudes

${ }^{19}$ Decreto 626/16 (BORA, 2016). 


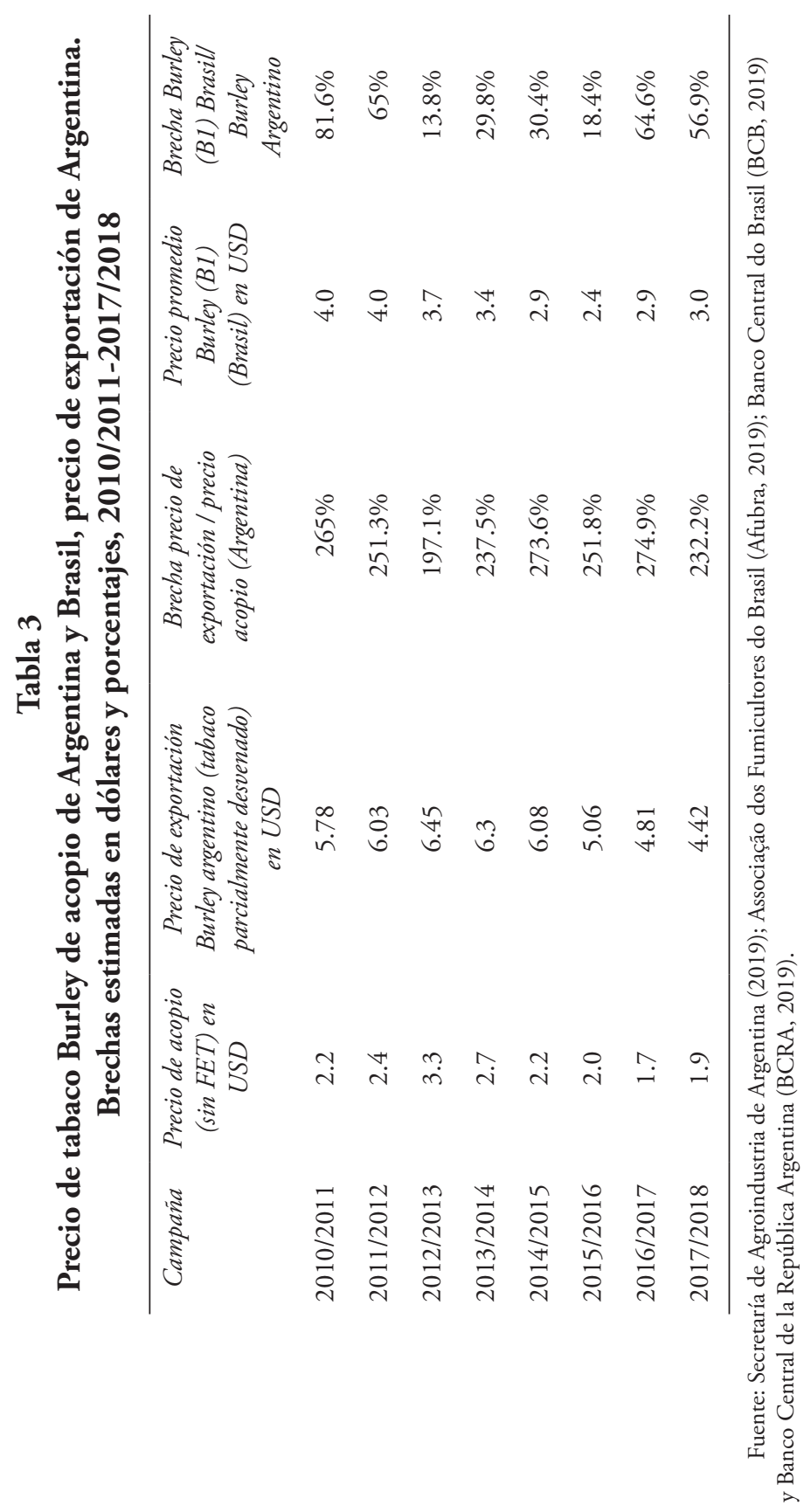


productivas. La misma varía entre $13.8 \%$ (2012/13) y 81.6\% (2010/11), siempre ubicando a los precios de Brasil por encima de los de Argentina a lo largo del período de estudio. Esta brecha de precios (medidos en dólares) refuerza lo señalado previamente acerca de que los valores que reciben los productores de Misiones se encuentran tendencialmente en un nivel relativamente bajo, lo que pone en riesgo su sustentabilidad.

\subsection{El alcance de los recursos del FET}

Otra de las derivaciones de la estructura concentrada de la industria tabacalera se refiere a la sustentabilidad económica, productiva y social de los pequeños productores. Para su análisis, se construyó una variable con base en la consideración de la magnitud de los fondos aportados por el FET. Para evaluar la relación existente entre el valor de mercado del tabaco y los recursos provistos por el FET, se elaboró un cociente como variable, construido por la suma de los subsidios distribuidos por el FET en el numerador, así como los ingresos recibidos por el productor mediante sobreprecio de acopio (subsidio directo) y mediante POAs, mientras que en el denominador se definió por el valor de acopio sin subsidios, siendo este último el precio fijado por el mercado (no competitivo). A continuación, se presenta la información sistematizada y los resultados en la tabla 4.

\section{Tabla $4^{20}$}

Valor del tabaco acopiado, precio acopio, precio FET y POAs, campańas 2010/11-2017/18 (en millones de pesos y porcentajes)

\begin{tabular}{lrrrrr}
\hline Campaña & $\begin{array}{c}\text { Valor de } \\
\text { acopio }\end{array}$ & $\begin{array}{c}\text { Valor del } \\
\text { subsidio FET }\end{array}$ & $\begin{array}{c}\text { Valor de } \\
\text { acopio total }\end{array}$ & POAs & $\begin{array}{c}\text { (Subsidios }+ \\
\text { POAs / Valor } \\
\text { de acopio) } \\
\text { (\%) }\end{array}$ \\
\hline $\mathbf{2 0 1 0 / 2 0 1 1}$ & $\mathbf{\$ 3 0 9 . 8}$ & $\mathbf{\$ 7 6}$ & $\mathbf{\$ 3 8 5 . 9}$ & $\mathbf{\$ 2 0 4 . 5}$ & \\
Burley & $\$ 305.6$ & $\$ 75$ & $\$ 380.6$ & $\$ 204.5$ & $\mathbf{9 0 . 5} \%$ \\
$\begin{array}{l}\text { Criollo } \\
\text { Misionero }\end{array}$ & $\$ 4.3$ & $\$ 1.1$ & $\$ 5.3$ & & \\
\hline 2011/2012 & $\mathbf{\$ 3 0 4 . 6}$ & $\mathbf{\$ 8 7 . 3}$ & $\mathbf{\$ 3 9 1 . 8}$ & $\mathbf{\$ 2 2 3 . 6}$ & \\
Burley & $\$ 300.4$ & $\$ 86.1$ & $\$ 386.5$ & $\mathbf{\$ 2 2 3 . 6}$ & $\mathbf{1 0 2 . 1 \%}$ \\
Criollo & $\$ 4.2$ & $\$ 1.2$ & $\$ 5.4$ & & \\
Misionero & & & & & \\
\hline
\end{tabular}

\footnotetext{
${ }^{20}$ No fueron incorporados los datos referidos al tabaco Criollo Argentino debido a su aporte marginal, próximo a las cinco toneladas.
} 
Tabla 4 (continuación)

\begin{tabular}{|c|c|c|c|c|c|}
\hline Campaña & $\begin{array}{l}\text { Valor de } \\
\text { acopio }\end{array}$ & $\begin{array}{c}\text { Valor del } \\
\text { subsidio FET }\end{array}$ & $\begin{array}{c}\text { Valor de } \\
\text { acopio total }\end{array}$ & POAs & $\begin{array}{c}\text { (Subsidios + } \\
\text { POAs / Valor } \\
\text { de acopio) } \\
\text { (\%) }\end{array}$ \\
\hline $2012 / 2013$ & $\$ 438.4$ & $\$ 89,4$ & $\$ 527.8$ & $\$ 424.9$ & \\
\hline Burley & $\$ 434.4$ & $\$ 88.6$ & $\$ 523$ & $\$ 424.9$ & $117.3 \%$ \\
\hline $\begin{array}{l}\text { Criollo } \\
\text { Misionero }\end{array}$ & $\$ 4.0$ & $\$ 0.8$ & $\$ 4.9$ & & \\
\hline $2013 / 2014$ & $\$ 659.7$ & $\$ 168.4$ & $\$ 828$ & $\$ 508.2$ & \\
\hline Burley & $\$ 655.1$ & $\$ 167.2$ & $\$ 822.3$ & $\$ 508.2$ & $102.6 \%$ \\
\hline $\begin{array}{l}\text { Criollo } \\
\text { Misionero }\end{array}$ & $\$ 4.5$ & $\$ 1.2$ & $\$ 5.7$ & & \\
\hline $2014 / 2015$ & $\$ 482.4$ & $\$ 154.3$ & $\$ 636.7$ & $\$ 741$ & \\
\hline Burley & $\$ 479.4$ & $\$ 153.3$ & $\$ 632.7$ & $\$ 741$ & $185.6 \%$ \\
\hline $\begin{array}{l}\text { Criollo } \\
\text { Misionero }\end{array}$ & $\$ 3.0$ & $\$ 1$ & $\$ 4$ & & \\
\hline $2015 / 2016$ & $\$ 457.5$ & $\$ 197.9$ & $\$ 655.4$ & $\$ 578.1$ & \\
\hline Burley & $\$ 454.2$ & $\$ 196.4$ & $\$ 650.6$ & $\$ 578.1$ & $169.6 \%$ \\
\hline $\begin{array}{l}\text { Criollo } \\
\text { Misionero }\end{array}$ & $\$ 3.3$ & $\$ 1.5$ & $\$ 4.8$ & & \\
\hline $2016 / 2017$ & $\$ 954.2$ & $\$ 323.3$ & $\$ 1,277.5$ & $\$ 1,608$ & \\
\hline Burley & $\$ 947.6$ & $\$ 320.9$ & $\$ 1,268.5$ & $\$ 1,608$ & $202.4 \%$ \\
\hline $\begin{array}{l}\text { Criollo } \\
\text { Misionero }\end{array}$ & $\$ 6.6$ & $\$ 2.4$ & $\$ 9$ & & \\
\hline $2017 / 2018^{*}$ & $\$ 1,044.5$ & $\$ 577.1$ & $\$ 1,621.5$ & $\$ 2,142.5$ & \\
\hline Burley & $\$ 1,036.1$ & $\$ 572.1$ & $\$ 1,608.3$ & $\$ 2,142.5$ & $260.4 \%$ \\
\hline $\begin{array}{l}\text { Criollo } \\
\text { Misionero }\end{array}$ & $\$ 8.4$ & $\$ 4.9$ & $\$ 13.3$ & & \\
\hline
\end{tabular}

Fuente: elaboración propia con base en la Secretaría de Agroindustria (2019) y Ministerio de Hacienda (2018).

La tabla 4 indica con claridad la relevancia creciente del FET en la economía del tabaco de la provincia de Misiones. De acuerdo con la sistematización realizada, los fondos aportados por el FET superan con holgura el valor asignado por el mercado a la producción de tabaco, ya que duplican o triplican a este último. Concretamente, en la campaña 2010/11 los 
aportes del FET representaron 90.4\% del valor de acopio, mientras que en la campaña 2017/18 representaron 260.4\%, lo cual marca una evolución creciente. Esto significa que sin la contribución del FET (ya sea mediante el subsidio o los POAs) la producción y venta de tabaco implicaría una pérdida económica para los pequeños productores. Sobre este punto resulta de interés mencionar que si bien ellos identifican la fuente de cada uno de sus ingresos, la importancia de los recursos del FET en su sostenibilidad tiende a generar una subestimación en los costos de producción y de las condiciones establecidas por la empresa acopiadora (García, 2010).

En forma resumida, se observa que la distribución (de un promedio teórico) de los ingresos agregados de los productores se ordena del siguiente modo: a) su primera fuente de ingresos son los POAs, b) el valor de acopio de mercado y c) el subsidio directo implementado por el FET en forma de sobreprecio. En términos más simples, para el caso de la campaña $2017 / 2018$, de cada $\$ 100$ percibidos por los productores, $\$ 57$ fueron aportados por los planes, $\$ 28$ por el precio de acopio y $\$ 15$ por el sobreprecio.

La información obtenida y sistematizada sobre los recursos aportados por el FET hacia la producción tabacalera de la provincia de Misiones permite comprender el rol de dicha política pública en el sostenimiento de la actividad. Si bien por un lado sostiene dentro del circuito económico a más de 13,000 pequeños productores de la provincia, por otro su inter-

\section{Gráfica 2 \\ Participación porcentual de las fuentes de ingresos de los productores tabacaleros, campańa 2017/18}

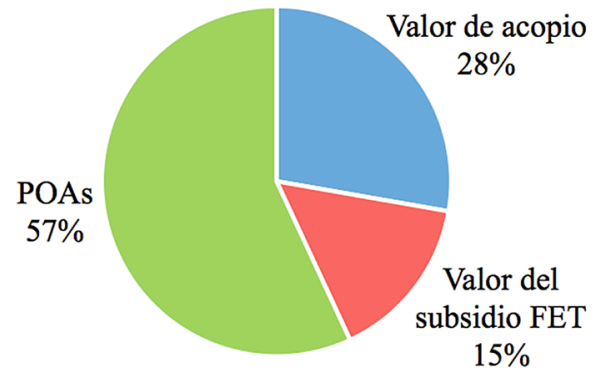

" Valor de acopio " Valor del subsidio FET " POAs

Fuente: elaboración propia con base en la Secretaría de Agroindustria (2019) y el Ministerio de Hacienda (2018). 
vención le asegura una mayor apropiación de valor a las empresas concentradas respecto a una situación de competencia. En ausencia de herramientas estatales integrales y sistemáticas que regulen la actividad y promuevan cambios en la relación de fuerza entre los actores de la cadena, la intervención estatal sostiene y reproduce la relación de dependencia entre productores primarios e industriales.

\section{Reflexiones finales}

El rol de la intervención estatal en la construcción y/o sostenimiento de los mercados constituye un amplio campo de debate económico, sociológico y político. En particular, en el presente trabajo se buscó aportar (mediante el estudio de caso con información empírica) elementos para la comprensión del vínculo existente entre el Estado y sus políticas públicas, y el mercado, en este caso, el mercado tabacalero de la provincia de Misiones. El estudio permitió definir su estructura básica y las principales problemáticas económicas y sociales.

De este modo, dada una dinámica caracterizada por la agricultura bajo contrato en la cual existen escasos agentes compradores de la materia prima del tabaco, estos obtienen un excedente sensiblemente superior en comparación con un escenario teórico de competencia, lo que repercute de forma directa en menores ingresos para los pequeńos productores. Es aquí en donde la intervención de las políticas públicas, mediante subsidios provenientes del FET para el caso del mercado tabacalero, tienen lugar. Tal como se desarrolló en el trabajo, los recursos que aporta dicho fondo tienen una importancia creciente sobre los ingresos que reciben los agentes del sector primario a lo largo del período de estudio. Este elemento permite inferir que, sin este aporte, probablemente muchos productores no podrían sostener su actividad. Pero al mismo tiempo se encuentra la otra cara de la moneda, porque dichos recursos brindan condiciones a las empresas para pagar un precio de acopio menor al que se pagaría en condiciones competitivas. Con base en lo anterior, se puede inferir que los recursos del FET también constituyen un subsidio al capital concentrado de la cadena de valor tabacalera.

Por ende, en contraposición de lo que pregona la teoría económica convencional, el Estado genera condiciones y tiene las herramientas para contribuir a la creación o al sostenimiento de mercados específicos, los cuales no son autorregulados ni se guían por el precio de libre competencia. El presente trabajo de investigación realiza una contribución sobre la temática mediante el estudio del caso del FET en la provincia de Misiones, 
aportando elementos de carácter empíricos, los cuales deberán ser profundizados en investigaciones futuras.

\section{Fuentes consultadas}

Afubra (Associação dos Fumicultores do Brasil) (2019), “Tabela do preco do fumo 17 18_Alliance_Universal”, Brasilia, Associação dos Fumicultores do Brasil, <https://afubra.com.br/content/arquivo_ tabela/Tabela\%20de\%20preco\%20do\%20fumo\%2017\%2018_ Alliance_Universal.pdf>, 15 de diciembre de 2019.

AGN (Auditoría General de la Nación) (2018), "Auditoría de Gestión. Coordinación de área Tabaco, Fondo Especial de Tabaco. Proyecto No. 121631", Ciudad Autónoma de Buenos Aires, Auditoría General de la Nación, <https://www.agn.gob.ar/sites/default/files/ informes/informe_066_2018.pdf>, 15 de noviembre de 2019.

Aparicio, Susana (2009), "Trabajos y relaciones de trabajo en la producción tabacalera empresarial”, Revista Interdisciplinaria de Estudios Agrarios, núm. 30, Ciudad Autónoma de Buenos Aires, Centro Interdisciplinario de Estudios Agrarios, pp. 17-44, <http://www. ciea.com.ar/web/wp-content/uploads/2016/11/RIEA30-03.pdf>, 2 de febrero de 2020 .

Arzeno, Mariana Beatriz; Deheza, Rocío del Pilar; Muñecas, Lucila y Zanotti, Aymara Suyai (2015), "Discusiones en torno a las políticas públicas para la soberanía alimentaria y la agricultura familiar en Misiones (Argentina)", Mundo Agrario, 16 (32), La Plata, Centro de Historia Argentina y Americana (UNLP), pp. 1-27, $<$ https://www.mundoagrario.unlp.edu.ar/article/view/ MAv16n32a05>, 22 diciembre de 2019.

BCB (Banco Central do Brasil) (2019), "Série de Estadísticas consolidadas", Ciudad de Brasilia, Banco Central do Brasil, <https://www3. bcb.gov.br/sgspub/pefi300/consultarDolarOuro.paint?method= consultarValoresDolarOuro>, 10 de enero de 2020.

BCRA (Banco Central de la República Argentina) (2019), "Estadísticas cambiarias", Ciudad Autónoma de Buenos Aires, Banco Central de la República Argentina, <http://www.bcra.gov.ar/PublicacionesEstadisticas/Tipos_de_cambios.asp>, 10 de enero de 2020. 
BORA (Boletín Oficial de la República Argentina) (2016), "Ley núm. 24.674. Fíjase gravamen. Decreto 626/16”, 29 de abril de 2016, Buenos Aires, Legal y Técnica de la Presidencia de la Nación Argentina, <https://www.boletinoficial.gob.ar/detalleAviso/prim era/ $144503 / 20160502$ ? busqueda $=1>5$ de mayo de 2020 .

BORA (Boletín Oficial de la República Argentina) (2009), "Modificación Ley núm. 24.674 y de la Ley 19.800, Ley 26.467”, 09 de enero de 2009, Buenos Aires, Legal y Técnica de la Presidencia de la Nación Argentina, <https://www.boletinoficial.gob.ar/detalleAviso/primera/9293649/20090109? busqueda $=1>, 6$ de mayo de 2020 .

BORA (Boletín Oficial de la República Argentina) (1993), "Tabaco, Ley 24.291", 29 de diciembre de 1993, Buenos Aires, Legal y Técnica de la Presidencia de la Nación Argentina, <https://www.boletinoficial.gob.ar/detalleAviso/primera/7139901/19931229?busqu eda $=1>, 5$ de mayo de 2020 .

BORA (Boletín Oficial de la República Argentina) (1991a), "Desregulación económica, Decreto, 2284/91", 1 de noviembre de 1991, Buenos Aires, Legal y Técnica de la Presidencia de la Nación Argentina, <https://www.boletinoficial.gob.ar/detalleAviso/prim era/7125374/19911101? busqueda $=1>, 5$ de mayo de 2020 .

BORA (Boletín Oficial de la República Argentina) (1991b), "Desregulación económica, Decreto 2488/91”, 28 de noviembre de 1991, Buenos Aires, Legal y Técnica de la Presidencia de la Nación Argentina, <https://www.boletinoficial.gob.ar/detalleAviso/prim era/7125823/19911128?busqueda=1>, 6 de mayo de 2020 .

BORA (Boletín Oficial de la República Argentina) (1972), "Fondo Especial del Tabaco, Ley 19,800”, 31 de agosto de 1972, Buenos Aires, Legal y Técnica de la Presidencia de la Nación Argentina, <https:// www.boletinoficial.gob.ar/detalleAviso/primera/7048196/1972 0831 ?busqueda=1>, 30 de abril de 2020 .

BORA (Boletín Oficial de la República Argentina) (1967), "Tabaco. Reglaméntase la Ley 17,175”, 16 de mayo de 1967, Buenos Aires, Legal y Técnica de la Presidencia de la Nación Argentina, <https:// www.boletinoficial.gob.ar/detalleAviso/primera/10809849/196 70516? busqueda=1>, 30 de abril de 2020 . 
Colombo, Octavio (2008), "Karl Polanyi y el problema de los mercados", Studia Historica. Historia Antigua, vol. 26, Salamanca, Universidad de Salamanca, pp. 221-236, <https://www.researchgate.net/ publication/41003069_Karl_Polanyi_y_el_problema_de_los_ mercados>, 15 de diciembre de 2019.

Díaz-Cano Eduardo y Tardivo, Giuliano (2016), "La sociología y los mercados: una aproximación”, en Diego Santos González y Silvia Giménez Rodríguez (coords.), Integraciones y desintegraciones sociales, Toledo, Asociación Castellano-Manchega de Sociología, pp. 215-239, <https://acmspublicaciones.revistabarataria.es/wpcontent/uploads/2017/05/16.Eduardo.Valdep.2016.215_239. pdf>, 2 de agosto de 2020 .

Diez, María Carolina y Re, Daniel Alberto (2015), "El Complejo Agroindustrial tabacalero. Un análisis sobre las transformaciones socioproductivas en las provincias argentinas de Jujuy y Misiones", Revista Antropolitica, núm. 39, Niterói, Universidade Federal Fluminense, pp.179-213, <https://ri.conicet.gov.ar/bitstream/ handle/ $11336 / 38341 / 395-857-1$ - P B . pdf? sequence $=5$ \&isAllowed $=y>, 14$ de diciembre de 2019 .

Diez, María Carolina (2010), “Análisis de la 'tutela' estatal en la producción de tabaco Burley (Misiones, Argentina), significados y disputas", Cadernos de Campo, núm. 19, São Paulo, Universidade de São Paulo, pp. 151-164, <https://ri.conicet.gov.ar/bitstream/ handle/11336/43603/CONICET_Digital_Nro.bbae7318-d3a64247-a7bf-32b349f94c4b_A.pdf?sequence=2\&isAllowed=y>, 13 de diciembre de 2019.

Dirección General de Rentas de la provincia de Misiones (2019), "Dirección General de Rentas. Provincia de Misiones", Ciudad de Posadas, Provincia de Misiones, Argentina, <https://www.dgr. misiones.gov.ar/portal/index.php/informacion-fiscal-n/documentacion-y-estadisticas/graficos-de-recaudacion/1572-graficorecaudacion-publicado-en-2019>, 5 de febrero de 2020.

Fernández, Lisandro (2016), "Las políticas para la agricultura familiar. Características y tendencias de tres programas en la provincia de Misiones", Geograficando, 12 (2), La Plata, Departamento de Geografía de la Facultad de Humanidades y Ciencias de la Educación de la Universidad Nacional de La Plata, pp. 1-16, <https:// 
www.geograficando.fahce.unlp.edu.ar/article/download/ Geoe011/7849?inline=1>, 1 de febrero de 2020 .

Fligstein, Neil y Dauter, Luke (2007), "The Sociology of Markets", Annual Review of Sociology, núm. 33, Palo Alto, Annual Review, pp. 105-128, doi: 10.1146/annurev.soc.33.040406.131736

García, Ariel (2014), "Políticas Públicas y Agroindustrias: ¿para qué desarrollo regional? Las experiencias de Fondo Especial del Tabaco (FET) y el Programa Vitivinícola (PROVIAR) de la Argentina de la postconvertibilidad", en Alejandro Rofman y Ariel García (comps.), Economía solidaria y cuestión regional en Argentina de principios de siglo XXI, entre procesos de subordinación y prácticas alternativas, Ciudad Autónoma de Buenos Aires, Centro de Estudios Urbanos y Regionales, pp. 120-154, <https://www. centrocultural.coop/sites/www.centrocultural.coop/files/blogs/ cooperativismo/wp-content/uploads/2014/01/economia-solidaria-y-cuestion-regional-en-arg-s-xxi-ok051.pdfs, 30 de noviembre de 2019.

García, Ariel (2010), "Más allá de lo aparente: contratos de producción Más allá de lo aparente: contratos de producción tabacalera en Misiones (Argentina) y Río Grande tabacalera en Misiones (Argentina) y Río Grande do Sul (Brasil) do Sul (Brasil)", Realidad Económica, núm. 254, Ciudad Autónoma de Buenos Aires, Instituto Argentino para el Desarrollo Económico (IADE), pp. 135-154.

Marradi, Alberto; Archeti, Nélida y Piovani, Juan (2012), Metodología de las Ciencias Sociales, Buenos Aires, Cengage Learning Argentina.

Ministerio de Agricultura, Ganadería y Pesca (s/f), "Actores que intervienen en la cadena de valor del tabaco", Ciudad Autónoma de Buenos Aires, Ministerio de Agricultura, Ganadería y Pesca, $<$ https://www.magyp.gob.ar/sitio/areas/tabaco/informes/cadena valor/_archivos//000000_Actores\%20que\%20intervienen\%20 en $\% 201$ a $\% 20$ cadena $\% 20$ de $\% 20$ valor\%20del\%20tabaco.pdf>, 10 de agosto de 2020 .

Ministerio de Hacienda (2019), "Informe de cadenas de valor. Tabaco", Ciudad Autónoma de Buenos Aires, Ministerio de Hacienda, Subsecretaría de Programación Microeconómica, Secretaría de Política Económica, <https://www.argentina.gob.ar/sites/ 
default/files/sspmicro_cadenas_de_valor_tabaco_1.pdf>, $16 \mathrm{de}$ enero de 2020.

Ministerio de Hacienda (2018), "Informes productivos provinciales. Misiones", núm. 19, Ciudad Autónoma de Buenos Aires, Ministerio de Hacienda, Subsecretaría de Programación Microeconómica, Secretaría de Política Económica, <https://www.argentina. gob.ar/sites/default/files/informe_productivo_misiones.pdf>, 18 de enero de 2020.

Ministerio de Hacienda y Finanzas (2016), "Tabaco, informes de cadena de valor", núm. 32, Ciudad Autónoma de Buenos Aires, Ministerio de Hacienda y Finanzas, Subsecretaría de Política Económica y Planificación del Desarrollo, <https://www.economia.gob.ar/ peconomica/docs/SSPE_Cadenas\%20de\%20valor_Tabaco.pdf $>$, 16 de enero de 2020.

Ministerio de Justicia y Derechos Humanos (1995), “Apruébese acta final en el que se incorporan los resultados de la Ronda Uruguay de Negociaciones comerciales Multilaterales, las Decisiones, Declaraciones y Entendimientos Ministeriales y el Acuerdo de Marrakech, Ley 24,425”, 5 de enero de 1995, Buenos Aires, Información Legislativa, Argentina, <http://servicios.infoleg.gob. ar/infolegInternet/anexos/0-4999/799/norma.htm>, 5 de agosto de 2020.

Misiones Online (2018), "Tabacaleros sellaron el acuerdo de precios y este jueves arranca el acopio", Misiones Online: 14 de marzo de 2018, Posadas, Misiones, Argentina, Agro y Producción, <https:// misionesonline.net/2018/03/14/tabacaleros-sellaron-acuerdoprecios-lunes-arranca-acopio/>, 21 de noviembre de 2019.

Polanyi, Karl (2011), La gran transformación. Los orígenes políticos y económicos de nuestro tiempo, Buenos Aires, Fondo de Cultura Económica.

Scheinkerman de Obschatko, Edith (2009), Las explotaciones agropecuarias familiares en la República Argentina, Ciudad Autónoma de Buenos Aires, Instituto Interamericano de Cooperación para la AgriculturaArgentina, <http://redaf.org.ar/wp-content/uploads/2013/07/ ESTINV.23.Las\%20EAP\%20Familiares\%20en\%20la\%20Republica\%20Argentina.pdf>, 16 de diciembre de 2019. 
Schiavoni, Gabriela; Perucca, Clorinda; Schorer, Esther y Otero Correa Natalia (2006), "Desarrollo rural alternativo: relaciones entre el Estado, las ONG's y los productores en la provincia de Misiones (Argentina)", en Mabel Manzanal, Guillermo Neiman y Mario Lattuada (coords.), Desarrollo rural: organizaciones, instituciones y territorios, Buenos Aires, CICCUS (Centro de Integración Comunicación Cultura y Sociedad), pp. 251-268.

Secretaría de Agroindustria (2019), "Programa de reconversión de áreas tabacaleras 2018. Área acopio, producción, estudios y finanzas", Ciudad Autónoma de Buenos Aires, Secretaría de Agroindustria, $<$ https://www.magyp.gob.ar/sitio/areas/tabaco/produccion_mercados/externo/_archivos/000000_Exportaciones/000018_ Exportaci\%C3\%B3n\%202018.pdf>, 14 de diciembre de 2019.

Sturzenegger, Adolfo (2016), "Una Economía Regional en Sobrevivencia Involutiva: El tabaco Virginia en Jujuy y la Comercialización Monopsónica”, Documento de Trabajo núm. 110, Ciudad de La Plata, Departamento de Economía e Instituto de Investigaciones Económicas, Facultad de Ciencias Económicas, Universidad Nacional de La Plata, <http://sedici.unlp.edu.ar/bitstream/ handle/10915/65780/Documento_completo.pdf-PDFA. pdf?sequence $=1$ \&isAllowed $=y>, 25$ de noviembre de 2019 .

Swedberg, Richard (2003), "The Economic Sociology of Capitalism: An Introduction and Agenda", Nueva York, Center for the study of Economy \& Society, <https://www.economyandsociety.org/wpcontent/uploads/2013/08/wp5a_swedberg_03.pdf>, 19 de noviembre de 2019.

Watts, Michael (1990), "Peasants under contract: agro-food complexes in the Third World", in Henry Berstein; Ben Crow; Maureen Mackintosh y Charlotte Martin (edit.), The food question: profits versus people, Nueva York, Monthly Review Press, pp.149-162.

Recibido: 21 de febrero de 2020. Reenviado: 13 de agosto de 2020. Aceptado: 20 de agosto de 2020.

Lisandro Federico Fernández. Doctor en Ciencias Sociales por la Universidad Nacional de La Plata (UNLP). Actualmente es becario posdoctoral 
del Consejo Nacional de Investigaciones Científicas y Técnicas (Conicet) y docente de la Facultad de Humanidades y Ciencias de la Educación (UNLP). Su línea de investigación actual está referida a la sociología rural y en particular en el estudio de las políticas públicas para la agricultura familiar en las provincias de Buenos Aires y Misiones (Argentina). Entre sus más recientes publicaciones se destacan, como autor: "Análisis de las políticas públicas para la agricultura familiar. Estudio de casos: La Plata y Oberá, 2008-2015”, Estudios Socioterritoriales, núm. 26, pp. 1-20, Buenos Aires, Centro de Investigaciones Geográficas, Instituto de Geografía, Historia y Ciencias Sociales, Facultad de Ciencias Humanas UNCPBA/Conicet (2019); "La exclusión social de los agricultores familiares de La Plata. Un análisis del período 2005-2018”, Pilquen, sección ciencias sociales, 21 (2), Viedma, Universidad Nacional del Comahue, Centro Universitario Regional Zona Atlántica, pp.106-123 (2018), y en coautoría: "Viejos sujetos, nuevos reclamos. Conflictos en la horticultura platense ayer y hoy", Estudos Sociedade e Agricultura, 26 (2), Río de Janeiro, Universidade Federal Rural do Rio de Janeiro, pp. 257-284 (2018).

Leandro Tomas Amoretti. Especialista en Economía Política con mención en Economía Argentina por la Facultad Latinoamericana de Ciencias Sociales (FLACSO) y licenciado en Economía por la Universidad Nacional de La Plata (UNLP). Actualmente es profesor del Colegio Nacional Rafael Hernández, Universidad Nacional de La Plata (UNLP). Su línea de investigación actual es la renta agropecuaria. Entre sus más recientes publicaciones se encuentran, como autor: "Derecho a la ciudad, mercado del suelo y movimientos populares. El caso de La Plata”, en Mariano Féliz, Emiliano López y Matías García (coords.), Desarmando el modelo. Desarrollo, conflicto y cambio social: debate tras una década de neodesarrollismo, Buenos Aires, El Colectivo, pp. 279-293 (2016); como coautor: "Una vez más sobre mediciones de rentabilidad y renta agraria en el agro pampeano: ¿Qué sabemos, qué podemos suponer con cierto grado de certeza y qué necesitamos indagar con mayor profundidad?", ponencia presentada en el VI Congreso de Economía Política: La economía Argentina bajo una encrucijada, Ciudad Autónoma de Buenos Aires, Centro Cultural de la Cooperación, Universidad Nacional de Quilmes, pp. 1-24 (2019). 